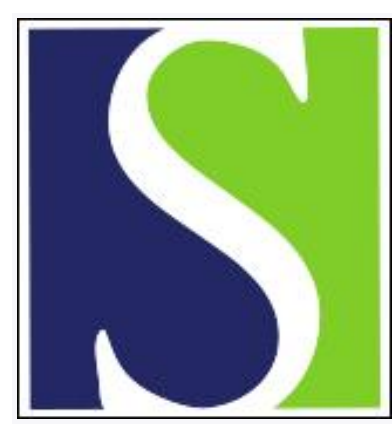

Scand J Work Environ Health 1975;1(1):40-44

https://doi.org/10.5271/sjweh.2862

Issue date: Mar 1975

Roentgenographic findings of the lumbosacral spine in preemployment examinations of lumbermen with special reference to spondylolisthesis.

by Parvi V, Virolainen $M$

Key terms: back; back disease; health examination; lumber work; lumberman; lumbosacral spine; lumbosacral spondylolisthesis; preemployment; preemployment examination; roentgenographic finding; roentgenography; spine; spondylolisthesis

This article in PubMed: www.ncbi.nlm.nih.gov/pubmed/1235856 


\title{
Roentgenographic findings of the lumbosacral spine in preemployment examinations of lumbermen with special reference to spondylolisthesis
}

\author{
by VESA PARVI, M.D., and MARKKU VIROLAINEN, M.D.
}

\begin{abstract}
PARVI, V. and VIROLAINEN, IM. Scand, $j$. work environ. \& health 1 (1975) $40-44$. The X-ray findings of the lumbar spine in the preemployment examination of 807 lumbermen are presented. From the applicants $11.4 \%$ were rejected because of roentgenological and/or clinical low back abnormalities. The youngest age group showed a high frequency of spondylolisthesis $(8 \%$ ). The possible role of heavy work in adolescence in the etiology of spondylolisthesis is discussed.

Key words: preemployment health examination, back diseases, lumbosacral spine, spondylolisthesis, lumber work.
\end{abstract}

Back troubles are an essential cause of lost working time and disability, especially in physically demaryding occupations with stress on the back. Advance identification of risk groups has been attempted by inspecting roentgenograms of the Iumbosacral spine in preemployment examinations. Choosing predictable and valia criteria of rejection has presented difficulties, since in the lumbosacral region there occur great numbers of roentgenological abnormalities not causing clinical symptoms, while back pain and insuifficiency may occur in persons with perfectly normal X-ray findings. The Industrial Medical Association's (IMA's) Ad Hoc Comm mittee on Low Back $X$-rays (3) and other authors $(5,6,7,12,19,20)$ are of the opinion that at least the following $X$-ray findings predict back troubles and form grounds of rejection for applicants in heavy occupations: spondylolisthesis, transitional Iumbosacral vertebra with pseudoarthrosis,

1. Department of Public Health, University of Jyväskylä, Jyväskylä, Finland.

Reprint requests to: Vesa Parvi, M.D., Departw ment of Public Health, University of Jyväskylä, 40100 Jyväskylä 10, Finland. true spina bifida, collapsed or wedged vertebra, evidence of old fractures of a vertebral body or a neural arch, prior back surgery (laminectomy or fusion), articulation of a transverse process with the sacrum, marked scoliosis with rotation or kyyphosis of the lumbar spine, and marked narrowing of an intervertebral joint space and advanced osteoarthritis if in excess of average usual findings in relation to age. As it appears, there is no unanimous agreement about the predetermining validity of the findings, and X-ray examinaw tions in preemployment examinations have even been regarded as completely useless (14).

On the whole, the occupation of lumberman consists of extremely heavy physical labor, and lifting logs and bending with a chain saw puts stress on the back and the limbs particularly. In an investigation conducted in Sweden (13) $39 \%$ of the lumbermen studied reported having received medical treatment from a doctor or in the hospital because of back pain; $5 \%$ of the younger (25 to 34 years) and $14 \%$ of the older ( 45 to 54 years) reported suffering from recurrent fits of lumbago 
or sciatica. Correspondingly, recurrent stiffness, pain or tiredness occurred in $25 \%$ and $50 \%$ of the cases. In the medical examination the following diagnoses were obtained: $20 \%$ of the younger and $27 \%$ of the older lumbermen showed dorsalgia and insufficientia dorsi, and correspondingly $16 \%$ and $24 \%$ lumbago-sciatica. The number of diagnoses per case was found higher than that in similar population studies in other groups. The dif.. ference can be explained by the higher incidence of back diseases in lumbermen. In a sample studied in Finland, which represented all the lumbermen of the country, $47 \%$ complained of back pain during the two previous years, and the incidence of back pain seemed to correlate with the number of years of working with a chain saw (8). Of those who had changed to a lighter occupation, $70 \%$ suffered from back troubles.

From the above data it can be concluded that an X-ray examination of the lumbosaoral spine should be included in the preemployment examinations of lumbermen. This paper presents the results of a study of the low back X-ray findings of 807 Finnish lumbermen in a preemployment examination.

In winter the majority of lumbermen in Finland work in employments of short duration or are employed in jobs with a seasonal nature. In summer they float logs or work on their own small farms. Indus trialization and urbanization have caused a decrease in this population sector of the country. Recently there has been a tendency, especially among young men, to find lighiter and better-paid jobs of a less seascnal nature in the towns. The shortage of laborers in the rural areas as well as the increasing demands for training due to automation and reorganization have made it imperative for the Iumber companies to hire permanent year-round staff (8).

\section{SUBJECTS AND METHODS}

This study was made during the years 1971 and 1972, when two companies in central and northern Finland were arranging their lumbermen on a permanent basis. All of the 807 applicants, 18 to 52 years of age, had worked as lumbermen more or less continuously. In addition many had worked on farms and in itransportation and loading jobs. Those having been in mines or factories at some time were rare. The common factor was that they had always been doing physically heavy work, most of them even from the age of 14 to 16 years. The age distribution of the study subjects is presented in table 1 .

The procedure of the study was as follows: The applicants filled out a standardized questionnaire in reference to their earlier significant diseases and present symptoms, including inquiries about their backs. All the applicants were submitted to a detailed clinical examination involving among other things posture, muscle spasms and tenderness of back, its flexibility when beriding, and symptoms of possible root compression. The X-rays of the lumbosacral spine were taken on $20 \times 40 \mathrm{~cm}$ film in anteromposterior and lateral directions; also a lateral cone picture of the lumbosacral junction was taken when the subject was standing. Eighty per cent of the pictures were interpreted by the same radiologist. A diagnosis of spondyliolisthesis was made only when there was a distinct slipping of the vertebrall body.

Rejection of the applicants was made on the basis of earlier anamnestic information, their clinical state, and the statement of the radiologist considered together, but in cases of spondylolisthesis rejection was made even without clinical symptoms. The criteria for rejection on the basis of the $X$-ray findings alone were less severe than those recommended by the IMA Ad Hoc Committee.

\section{RESULTS}

Altogether 130 applicants $(16.1 \%$ were rejected. The number of those rejected because of their back totaled 92 , or $11.4 \%$, of the total. Table 1 lists the results according to age groups and grounds for rejection. Back diseases caused the rejection of $70.7 \%$ of the total number of re. jected applicants. Of the other diseases causing rejection, the commonest were cardiovascular diseases, traumatic vasospastic disease (Raynaud's phenomenon of occupational origin), osteoarthritis of the 
Table 1. Causes of rejection in the preemployment examinations of 807 lumbermen classified by age. Figures are expressed as percentages.

\begin{tabular}{|c|c|c|c|c|c|c|c|c|}
\hline \multirow[b]{2}{*}{$\begin{array}{l}\text { Age, } \\
\text { years }\end{array}$} & \multirow[b]{2}{*}{$\begin{array}{l}\text { Number } \\
\text { of men }\end{array}$} & \multirow[b]{2}{*}{$\%$} & \multirow[b]{2}{*}{$\begin{array}{c}\text { Total } \\
\text { rejections }\end{array}$} & \multirow[b]{2}{*}{$\begin{array}{c}\text { Rejected } \\
\text { because } \\
\text { of back }\end{array}$} & \multicolumn{4}{|c|}{ Cause of rejection for back diseases } \\
\hline & & & & & $\begin{array}{l}\text { Spondyl- } \\
\text { olisthesis }\end{array}$ & $\begin{array}{c}\text { Degenera- } \\
\text { tive } \\
\text { changes }\end{array}$ & $\begin{array}{l}\text { Congenital } \\
\text { anomalies }\end{array}$ & $\begin{array}{c}\text { X-ray } \\
\text { normal, } \\
\text { clinical } \\
\text { insufficiency } \\
\text { of back }\end{array}$ \\
\hline $\begin{array}{l}18-24 \\
25-39 \\
40-52 \\
\end{array}$ & $\begin{array}{l}175 \\
441 \\
191 \\
\end{array}$ & $\begin{array}{l}21.7 \\
54.6 \\
23.7\end{array}$ & $\begin{array}{l}13.3 \\
12.5 \\
27.2\end{array}$ & $\begin{array}{l}12.0 \\
10.0 \\
14.1\end{array}$ & $\begin{array}{l}8.0 \\
3.4 \\
2.6\end{array}$ & $\begin{array}{l}2.3 \\
5.0 \\
9.4\end{array}$ & $\begin{array}{l}1.1 \\
1.1 \\
0.5\end{array}$ & $\begin{array}{l}0.6 \\
0.5 \\
1.6\end{array}$ \\
\hline Total & 807 & 100 & 16.1 & 11.4 & 4.2 & 5.5 & 1.0 & 0.7 \\
\hline
\end{tabular}

limbs, and diabetes. As expected, their prevalence was higher in older than in younger age groups. At the moment of the examination approximately half of the youngest group and threenfourths of the oldest group of rejected candidates showed clinical symptoms of the back. In the oldest age group various degrees of degenerative changes were the commonest roentgenological findings detected in connection with back pain. In the youngest age group the most common cause of rejection was spondylolisthesis, the prevalence of which surpassed in this study the frequency generally noted in studied populations.

\section{DISCUSSION}

The pencentage of rejection due to back diseases in this study totaled $11.4 \%$, which was about the same as in some eartier studies $(19,20)$. Even higher figures, ranging from 16 to $28 \%$ have been given $(5,-12)$. The criteria vary in the studies. Different jobs involve different requirements and the question of rejection often leads to a compromise between two factors: the employer's tendency to hire workers of low disability risk and the supply of the workers available at the moment.

Our material revealed, starting from quite young age groups, a fairly high incidence of degenerative changes of the lumbar spine, narrowing of the intervertebral spaces, sclerosis of the vertebral plates, osteophyte formation, and arthrosis of the apophyseal joints. This observa- tion agrees with the results of previous studies, according to which those working in heavy occupations show these changes more frequently and at an earlier age than those in control groups performing less physically demanding wortk (1). Such studied groups are miners $(2,4,11)$, lum bermen (9), docks workens, and ilaborers in heavy industrial work (10). Owing to the lack of control material interpreted by the same radiologist, we refrained from making a closer description and classification of these ohanges. A mild or moderate convex scoliosis, particularly on the left side, which was a relatively common finding in our material, can be considered a change accompanying the oocupation. Work that involves bending with a chain saw results in a static positioning of the back in this direction.

The prevalence of spondylolisthesis in the $X$-rays of an unselected adult population is stated to be from 2 to $3 \%$ in various studies $(14,18,20$, among others). The present study showed a prevalence of $4.2 \%$; in the youngest age grioup it was $8 \%$, whidh differs significantly from the average $2.5 \%(p<0.01)$. An explanation should be sought - in addivion to mere coincidence - in view of the following possibilities:

1. Spondylolisthesis may be hereditary $(15,16,18)$. The majority of lumbermen included in this material were from north ern Finland, where genetic isolates and clustering of some hereditary diseases are known to occur (17). The possible family connections of the subjects have not been examined.

2. Prevalences of spondylolisthesis higher than the average have been en- 


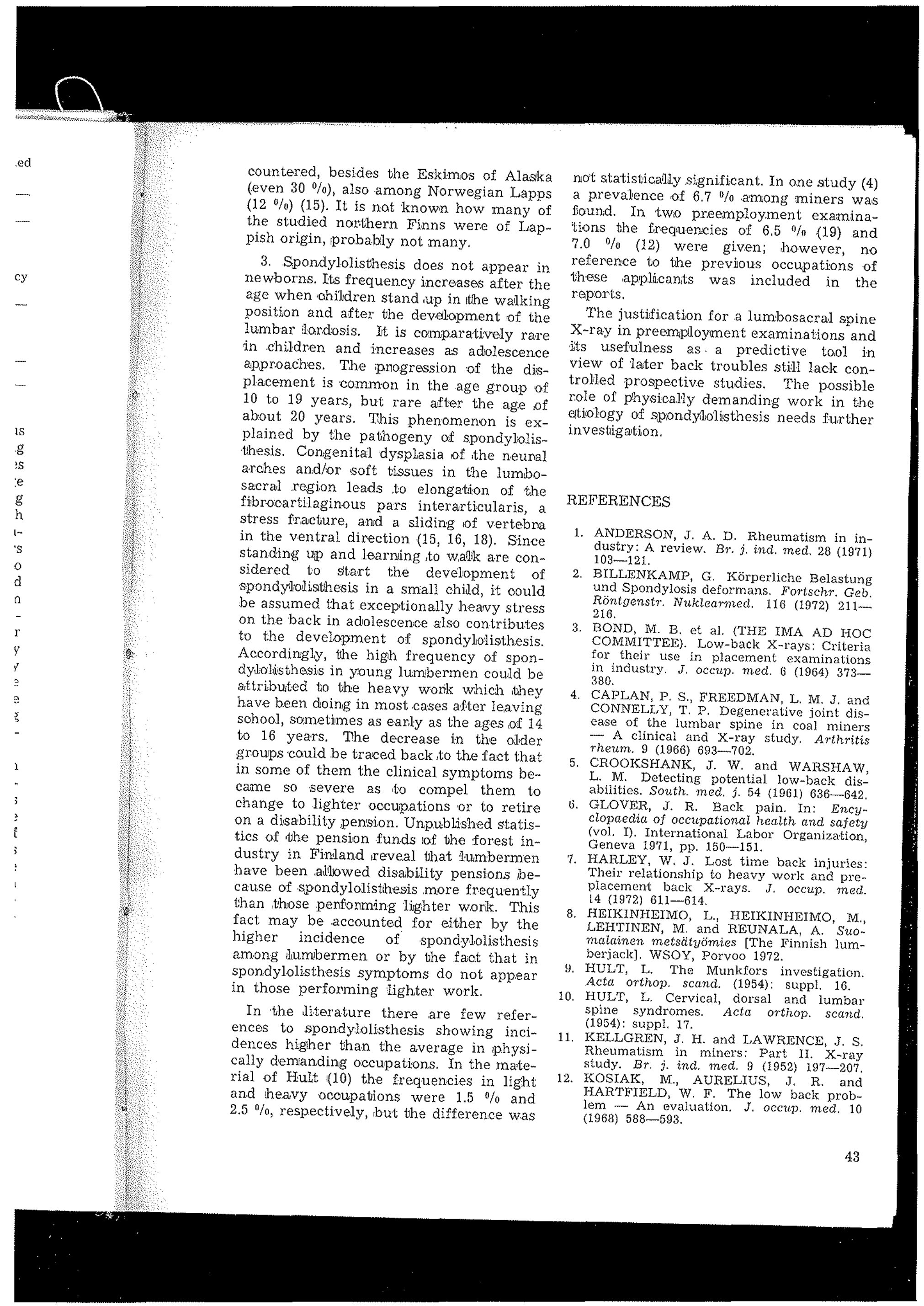


13. KYLIN, B., GERIIARDSSON, G., LIDSTROM, I.-MM., LILJENBERG, B., SWENSSON, A. and ASTRAND, I. Hälso- och miljöundersökning bland slcogsarbetare. Arbetsmediciniska Institutet, Stockholm 1968, pp. II-17.

14. LAROCCA, H. and NACNAB, I. Value of pre-employment radiographic assessment of the lumbar spine. Ind. med. surg. 39 (1970) $31-36$

15. LAURENT, L. E. Spondylolisthesis. Acta orthop. scand. (1958): suppl. 35.

16. LAURENT, L, E. and OSTERMAN, $\mathrm{K}$ Spondylolisthesis in children and adolescents: A study of 173 cases. Acta orthop. belg. 35 (1969) $717-727$.

Received for publication: 1974-01-15
17. NEVANLINNA, H. R. Suomen väestöraw kenne ja suomalainen tautiperintö tThe Finnish population structure and rare recessive diseases]. Duodecim 88 (1972) $4-14$.

18. NEWMAN, P. H. The etiology of spondylolisthesis. J. bone joint surg. [Br.] 45 (1963) $39-59$.

19. REDFIELD, J. T. The low back X-rays as a pre-employment screening tool in the forest products industry. J. occup. med. 13 (1971) $219-226$.

20. RUNGE, C. F. Roentgenographic examination of the lumbosacral spine in routine pre-employment examinations. $J$. bone joint surg. [Am.] 36 (1954) $75-84$. 